\title{
COVID-19 Vaccine Boosters for All Adults: An Optimal U.S. Approach?
}

\author{
Ameet Sarpatwari, PhD, JD; Ankur Pandya, PhD; Emily P. Hyle, MD, MSc; and Govind Persad, JD, PhD
}

B 20 October 2021, the U.S. Food and Drug Administration (FDA) had amended its Emergency Use Authorizations for immunocompetent adults who previously received the Pfizer-BioNTech, Moderna, or Johnson \& Johnson COVID19 vaccines. For the 2-dose Pfizer-BioNTech and Moderna vaccines, the FDA permitted a single booster dose for adults aged 65 years or older and adults aged 18 to 64 years at high-risk for severe COVID-19 or at high risk for occupational or institutional COVID-19 exposure. For the single-dose Johnson \& Johnson vaccine, the FDA permitted a single booster dose for all adults aged 18 or older. These eligibility schemes were endorsed by the Centers for Disease Control and Prevention shortly after FDA approval.

The Biden administration, meanwhile, has pledged that boosters will soon be available for all adults (1). Many experts have criticized boosters for unfairly drawing on the global vaccine supply when many countries have not yet been able to vaccinate even a tenth of their population. However, when compared with other uses of the same resources, will a U.S. booster-for-all policy be detrimental not only to the global community, but also for Americans? Answering this question requires estimating the relevant consequences of the policy relative to plausible alternative policies.

Data regarding the benefits and harms of boosters remain preliminary and limited. Although benefits include reductions in symptomatic infection, transmission, and severe infection leading to hospitalization or death, ongoing protection of initial vaccines against severe infection without a booster and the probability of higher booster uptake in regions with high initial uptake suggest that the magnitude of additional societal benefit with a booster-for-all policy will be small. In addition, these observational data are subject to confounding and limited to the single strategy of a third dose of Pfizer-BioNTech COVID-19 vaccine after its initial 2-dose series (2). Although reports of adverse events after boosters are rare, data are limited in younger individuals for whom the risk-benefit balance may be closer and the duration of improved response after booster is unknown (3).

By contrast, the costs of boosters to all U.S. adults can be estimated with more certainty. A single-dose booster for all prior recipients of the Pfizer-BioNTech vaccine alone would require 100 million doses. Despite stockpiled doses, further procurement will be needed. In July, the federal government agreed to purchase 200 million more doses from Pfizer at a cost of $\$ 24$ per dose (4). These doses will then need to be distributed and administered nationwide, which will incur additional costs; for instance, Medicare currently pays approximately $\$ 40$ for administration of a single dose (5).

Although the Biden administration claims that it can simultaneously administer boosters to all those eligible in the United States, vaccinate the unvaccinated in the United States, and deploy vaccines globally, tradeoffs are inevitable in both scope and speed of action given limited resources. For example, supply concerns delayed the shipment of international vaccine donations earlier this spring 2021 (6). Frequent changes to booster eligibility and requirements also divert resources from simpler strategies that could be more effective for pandemic control within the United States. We list 3 such alternative policies (Table).

First, the United States could expand its promotion of initial vaccine uptake. As of 30 October 2021, the CDC reported that about $20 \%$ of Americans aged 18 years or older had not received a single dose of any COVID-19 vaccine and $30 \%$ were only partially vaccinated (7). Increasing first or second administered doses will provide greater population-level protection against severe infections and transmissions than boosters. Bolstered spending on promoting vaccine uptake via efforts like guaranteed paid time off, supporting employer vaccine requirements, and combating misinformation could improve vaccine uptake among unvaccinated Americans. However, convincing the still-unvaccinated population will be challenging; among self-reported unvaccinated respondents to a recent poll, 59\% reported that they would "definitely not" get a free vaccine, if available (8).

Second, the United States could increase access to rapid COVID-19 testing. Availability of such tests lags far behind other countries, with kits scarce and priced beyond the reach of many households. Availability of accessible rapid testing in European countries with vaccination rates similar to those in the United States may have helped better combat the pandemic (9). As with promotion of vaccine uptake, however, additional issues must be considered, including the potential for false-positive and false-negative results and the extent to which people who test positive adhere to recommended precautions.

Third, Americans will also benefit if some portion of the doses now reserved as boosters for domestic recipients were instead used internationally. The United States could resell doses, purchase and donate doses, or trade places in delivery order to allow other countries to receive doses earlier. The logistics of getting these doses into arms globally is not trivial; some, though not all, recipient countries also need assistance with distribution planning and supplies (for example, cold storage equipment). However, the benefits of improving vaccination rates globally would redound to Americans by reducing cross-border spread of COVID-19 and potentially slow the emergence of COVID-19 variants. It could also spur improvements in global economic activity that strengthen global supply chains, reducing spikes in the cost of food and manufactured goods, and enable travel. 


\begin{tabular}{|c|c|c|}
\hline Policy & Potential U.S.-Specific Costs & Potential U.S.-Specific Benefits \\
\hline Providing boosters to all U.S. adults & $\begin{array}{l}\text { Diversion of current vaccine supply } \\
\text { Costs of purchasing vaccines beyond current supply } \\
\text { Distribution, storage, and administrative costs } \\
\text { Potential adverse events from boosters }\end{array}$ & $\begin{array}{l}\text { Improved clinical outcomes among those already } \\
\text { fully vaccinated } \\
\text { Possible reduction in transmission }\end{array}$ \\
\hline $\begin{array}{l}\text { Increasing promotion of initial vaccine uptake } \\
\text { in the U.S. }\end{array}$ & $\begin{array}{l}\text { Costs of vaccination promotion or education strategies } \\
\text { Distribution, storage, and administrative costs }\end{array}$ & $\begin{array}{l}\text { Increased protection from initial doses for unvacci- } \\
\text { nated individuals than from boosters for those } \\
\text { already vaccinated } \\
\text { Reduced transmission from initial doses than from } \\
\text { boosters } \\
\text { Impact likely larger given regions with less initial } \\
\text { vaccination have more transmission }\end{array}$ \\
\hline $\begin{array}{l}\text { Strengthening rapid testing as a mitigation } \\
\text { strategy in the U.S. }\end{array}$ & $\begin{array}{l}\text { Testing costs } \\
\text { Economic and social costs of false-positive and } \\
\text { false-negative test results }\end{array}$ & $\begin{array}{l}\text { Can be targeted to unvaccinated populations } \\
\text { (including children attending school or day care) } \\
\text { Does not draw on current vaccine supply }\end{array}$ \\
\hline Enabling other countries to access vaccines & $\begin{array}{l}\text { Diversion of current vaccine supply } \\
\text { Greater distribution, storage, and administrative } \\
\text { costs for international use than for domestic use } \\
\text { Potential to draw limited resources away from } \\
\text { current non-COVID-19 vaccination programs and } \\
\text { health care capacity }\end{array}$ & $\begin{array}{l}\text { Lower transmission from abroad into U.S. } \\
\text { Decreased chance of the emergence of variants } \\
\text { Increased global standing by addressing global dis- } \\
\text { parities in vaccine access } \\
\text { Improved global security by stabilizing economic ac- } \\
\text { tivity (e.g., PEPFAR) }\end{array}$ \\
\hline
\end{tabular}

PEPFAR = President's Emergency Plan for AIDS Relief.

More broadly, reduced COVID-19 transmission could create a more favorable global environment for U.S. goals such as increased stability, as has been seen with the President's Emergency Plan for AIDS Relief (PEPFAR) program for HIV/AIDS (10).

Transparent evaluation of the costs and benefits of a booster-for-all strategy compared with these 3 strategies is sorely needed, as well as the value judgments that go into defining those costs and benefits. For instance, should the direct medical benefits from boosters be worth more than indirect medical benefits from economic improvement? Unfortunately, policymakers have provided no such public accounting, nor is there a centralized, systematic, and urgent effort to collect data needed to assess these tradeoffs. Without these data or a transparent approach to decision making, limited resources may be suboptimally used and public trust damaged.

When embarking on any major health program, it is important to consider not only that program's immediate medical consequences but also the social and economic consequences of that program compared with alternative courses of action. This is particularly true when no single policy best achieves everything desired (for example, cases averted, low cost, equity). Engaging in a comprehensive evaluation of outcomes could help chart a course of action that best promotes the health and well-being of Americans.

From Program On Regulation, Therapeutics, And Law (PORTAL), Division of Pharmacoepidemiology and Pharmacoeconomics, Department of Medicine, Brigham and Women's Hospital and Harvard Medical School, Boston, Massachusetts (A.S.); Department of Health Policy and Management and Center for Health Decision Science, Harvard T.H. Chan School of Public Health, Boston, Massachusetts (A.P.); Medical Practice Evaluation Center and Division of Infectious Diseases, Massachusetts General Hospital and Harvard Medical School, Boston, Massachusetts (E.P.H.); and Sturm College of Law, University of Denver, Denver, Colorado (G.P.).
Disclosures: Disclosures can be viewed at www.acponline.org /authors/icmje/ConflictOflnterestForms.do?msNum=M21-3927.

Corresponding Author: Ameet Sarpatwari, PhD, JD, 1620 Tremont Street, Suite 3030, Boston, MA 02120; e-mail, asarpatwari@bwh.harvard.edu.

Author contributions are available at Annals.org.

Ann Intern Med. doi:10.7326/M21-3927

\section{References}

1. Press briefing by White House COVID-19 response team and public health officials. The White House. 24 September 2021. Accessed at www.whitehouse.gov/briefing-room/press-briefings/ 2021/09/24/press-briefing-by-press-secretary-jen-psaki-and-secretaryof-homeland-security-alejandro-mayorkas-september-24-2021/ on 31 October 2021.

2. Barda N, Dagan N, Cohen C, et al. Effectiveness of a third dose of the BNT162b2 mRNA-COVID-19 vaccine for preventing severe outcomes in Israel: an observational study. Lancet. 29 October 2021. [Epub ahead of print]. doi:10.1016/S0140-6736(21)02249-2

3. Krause PR, Fleming TR, Peto R, et al. Considerations in boosting COVID-19 vaccine immune responses. Lancet. 2021;398:13771380. [PMID: 34534516] doi:10.1016/S0140-6736(21)02046-8

4. Hopkins JS. U.S. buys 200 million Covid-19 vaccines from Pfizer and BioNTech at about $\$ 24$ a shot. Wall Street Journal. 23 July 2021. Accessed at www.wsj.com/articles/u-s-buys-200-millioncovid-19-vaccines-from-pfizer-and-biontech-at-about-24-a-shot-1162707 8710 on 31 October 2021.

5. Centers for Medicare \& Medicaid Services. Medicare COVID-19 vaccine shot payment. US Centers for Medicaid and Medicaid Services. 24 September 2021. Accessed at www.cms.gov/ medicare/covid-19/medicare-covid-19-vaccine-shot-payment on 31 October 2021.

6. Banco E. Vaccine supply fears motivated White House booster push. Politico. 20 September 2021. Accessed at www.politico.com/ news/2021/09/20/biden-vaccine-booster-supply-513134 on 31 October 2021. 
7. COVID data tracker. Centers for Disease Control and Prevention. 30 October 2021. Accessed at https://covid.cdc.gov/covid-datatracker/\#datatracker-home on 31 October 2021.

8. Kaiser Family Foundation COVID-19 vaccine monitor. Accessed at www.kff.org/coronavirus-covid-19/dashboard/kff-covid-19-vaccinemonitor-dashboard/ on 31 October 2021.

9. Pavelka M, Van-Zandvoort K, Abbott S, et al; CMMID COVID-19 working group. The impact of population-wide rapid antigen testing on SARS-CoV-2 prevalence in Slovakia. Science. 2021;372:635-641. [PMID: 33758017] doi:10.1126/science.abf9648

10. Daschle T, Frist B. Building prosperity, stability, and security through strategic health diplomacy: a study of 15 years of PEPFAR. Bipartisan Policy Center. July 2018. Accessed at https://bipartisanpolicy.org/download/?file=/ wp-content/uploads/2019/03/Building-Prosperity-Stability-and-SecurityThrough-Strategic-Health-Diplomacy-A-Study-of-15-Years-of-PEPFAR. pdf on 31 October 2021. 
Author Contributions: Conception and design: A. Pandya, G.

Persad, A. Sarpatwari.

Analysis and interpretation of the data: A. Sarpatwari.

Drafting of the article: A. Pandya, G. Persad, A. Sarpatwari.

Critical revision for important intellectual content: E.P. Hyle, A.

Pandya, G. Persad, A. Sarpatwari.

Final approval of the article: E.P. Hyle, A. Pandya, G. Persad, A.

Sarpatwari.

Administrative, technical, or logistic support: A. Sarpatwari.

Collection and assembly of data: A. Pandya, A. Sarpatwari. 